\title{
Review
}

\section{Role of lung volume and airway inflammation in obstructive sleep apnea}

\author{
Andras Bikov, MD, PhD*, Gyorgy Losonczy, MD, Dsc, Laszlo Kunos, MD \\ Department of Pulmonology, Semmelweis University, Budapest, Hungary
}

\section{A R T I C L E I N F O}

\section{Article history:}

Received 21 December 2016

Received in revised form

6 August 2017

Accepted 23 August 2017

Keywords:

Airway inflammation

Lung

Lung function

Obstructive sleep apnea

Sleep

\begin{abstract}
A B S T R A C T
Obstructive sleep apnea (OSA) is a prevalent disorder that affects not only the upper airways but also the intrathoracic airways. In this review, we summarize the results of studies on lung function and airway inflammation. We provide evidence that the alterations in intrathoracic airways observed in OSA are not purely consequences of mechanical trauma and oxidative stress during apneic events but have a causal role in the structural changes associated with OSA and increasing severity of this disorder.
\end{abstract}

(c) 2017 The Japanese Respiratory Society. Published by Elsevier B.V. All rights reserved.

\section{Contents}

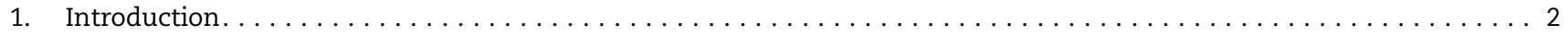

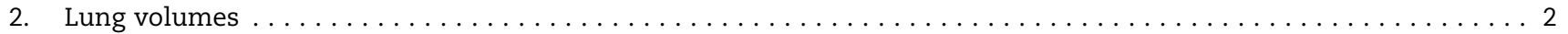

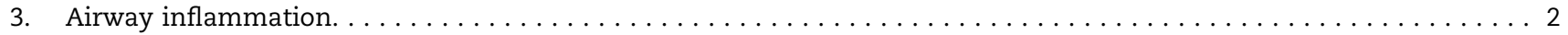

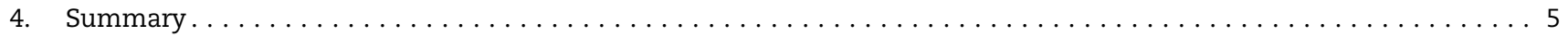

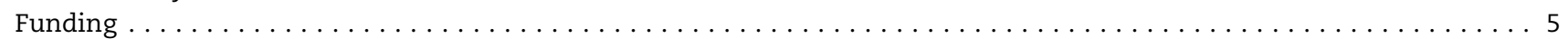

Abbreviations: AHI, apnea/hypopnea index; BALF, bronchoalveolar lavage fluid; BMI, body mass index; CIH, chronic intermittent hypoxia; COPD, chronic obstructive pulmonary disease; CPAP, continuous positive airway pressure; EBC, exhaled breath condensate; FENO, fractional exhaled nitric oxide; $\mathrm{FEV}_{1}$, forced expiratory volume in 1 second; FVC, forced vital capacity; ICAM, intercellular adhesion molecule; IL, interleukin; ILD, interstitial lung disease; iNOS, inducible nitric oxide synthase; MMP, matrix metalloproteinase;

OSA, obstructive sleep apnoea; TNF, tumor necrosis factor; VEGF, vascular endothelial growth factor

*Correspondence to: Department of Pulmonology, Semmelweis University, 1/C Dios arok, Budapest H-1125, Hungary. Fax: +3612142498 .

E-mail addresses: andras.bikov@gmail.com (A. Bikov), losonczygyrgy@gmail.com (G. Losonczy), laszlokunos@gmail.com (L. Kunos). 


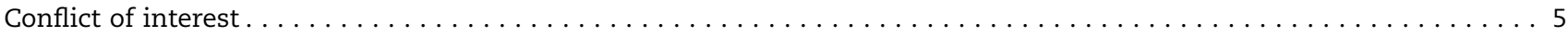

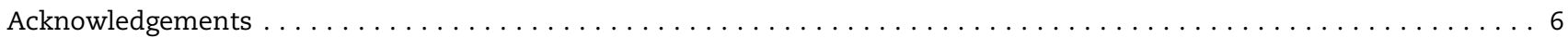

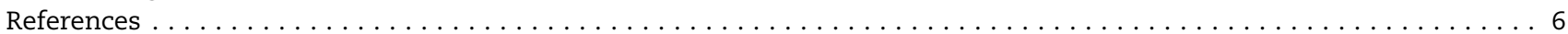

\section{Introduction}

Obstructive sleep apnea (OSA) is a common disorder that is characterized by repetitive episodes of total or partial collapse of the upper airways during sleep. If OSA is accompanied by symptoms of excessive daytime sleepiness, tiredness, or fatigue, the term obstructive sleep apnea syndrome is used. According to the latest edition of International Classification of Sleep Disorders issued by the American Academy of Sleep Medicine in 2014 [1], OSA is defined as either the presence of daily symptoms/disturbed breathing during sleep/comorbidities together with more than 5 obstructive respiratory events or more than 15 obstructive respiratory events, irrespective of symptoms or comorbidities. Because of the diversity of the diagnostic methods and criteria, the exact prevalence of OSA is not known, but it ranges between $10 \%$ and $30 \%$ in the general adult population [2]. Obesity, male sex, age, and craniofacial anatomy are the major determinants of OSA susceptibility [2]. Therefore, sociodemographic variations may contribute to diverse epidemiological results as well.

Decreased pharyngeal diameters and an increased possibility of upper airway collapse are important but not the only components of the OSA pathophysiology. Local and central nervous control and systemic inflammation are also frequently recognized factors. However, there has been little attention on the role of intrathoracic airways even though the lungs are under massive oxidative burden caused by chronic intermittent hypoxia (CIH). It seems that the lower airways do not just passively participate in OSA but may contribute to the complex pathophysiology of the disease as well.

This article aims to summarize the current knowledge on the role of lung volume and airway inflammation in OSA.

\section{Lung volumes}

It has been recognized that reduced lung volumes are related to increased OSA severity, regardless of whether the patients have airway or parenchymal lung disease. This relationship has been confirmed both by body plethysmography [3-6] and spirometry $[7,8]$. In particular, negative relationships were reported between the severity of OSA, determined using the apnea/ hypopnea index (AHI) or respiratory disturbance index, and expiratory reserve volume [3-6], functional residual capacity $[4,5]$, forced expiratory volume in one second $\left(\mathrm{FEV}_{1}\right)[7,8]$, and forced vital capacity (FVC) [7]. In line with this, a significant association between lung function loss and all-cause mortality was reported in patients with OSA [9]. However, the contribution of lung volume loss to mortality was lower in patients with sleep disordered breathing than in control subjects (6\% vs. $11 \%$, for every $200 \mathrm{~mL}$ decrease in $\mathrm{FEV}_{1}$ ) [10].

The relationship between reduced lung volume and OSA severity needs to be interpreted carefully because BMI is a strong covariate for this association [7]. Obesity reduces the functional residual capacity, especially in the supine position [11], and is strongly associated with OSA severity [11]. However, there are arguments that the association between lung volume and OSA severity is independent of obesity. First, the lung volume was reduced when patients with OSA were compared with BMI-matched controls [6,8]; the AHI and expiratory reserve volume were found to be related after correction for body mass index (BMI) [4]. Second, OSA is highly prevalent in non-obese patients with restrictive lung disease [12]. Third, reduced lung volume leads to upper airway collapse not only in patients with OSA but also in patients with chronic obstructive pulmonary disease (COPD) [13] and in healthy controls [14,15].

The association between lung volumes and upper airway collapsibility can be explained by mechanical [16] and chemical [17] factors [18]. A higher lung volume causes the mediastinal structures to be pulled caudally, leading to pharyngeal airway dilation [16]. Furthermore, increased lung volume is associated with the storage of more $\mathrm{O}_{2}$ and $\mathrm{CO}_{2}$, thus buffering blood gases from changes in ventilation [17]. Some patients with OSA are particularly prone to intermittent hypercapnic episodes, developing respiratory disturbances due to high loop gain [18].

Recently, we described an evening-to-morning increase in $\mathrm{FEV}_{1}$ in OSA without any change in FVC. This very mild bronchodilation may be caused by sympathetic bursts during apneic periods [7], but the exact reason needs to be investigated in detail. Of note, this increase was observed only in obese patients with OSA; there were no changes in non-obese subjects with OSA or obese control volunteers [7]. Tidal volumes tend to decrease at sleep onset in non-OSA patients of normal weight [19], as well as in non-OSA obese patients [11] and patients with OSA [20].

Continuous positive airway pressure (CPAP) treatment increases the vital capacity and functional residual capacity in non-OSA patients [21]. In addition, increases in lung volume are associated with lower pressures, required to maintain upper airway patency [14]. Thus, it seems that CPAP treatment prevents apneic episodes not only at the level of the upper airways but also by influencing the lower airway volumes. Of note, one study reported that long-term CPAP treatment is associated with worsening lung function, especially in terms of markers of small-airway obstruction [22].

Only one randomized controlled trial investigated if increasing the airway caliber with salmeterol has any effect on AHI in OSA; however, the effect of salmeterol compared to that of the placebo was insignificant [23].

\section{Airway inflammation}

Both chronic intermittent hypoxia and vibration trauma during snoring may induce inflammatory changes in the upper airways [24]. These include neutrophilia in the nasal 
lavage fluid $[25,26]$ and lymphocytosis in the pharyngeal lavage fluid $[27,28]$. In addition, OSA is characterized by an increase in the nasal levels of bradykinin and vasoactive intestinal peptide [25]. The resulting influx of inflammatory cells and the cytokine release may aggravate vasodilation, squamous cell hyperplasia, and hypertrophy of mucous glands. In addition, upper airway inflammation may lead to local anesthesia, which can blunt the physiological dilator reflex. Systemic inflammation augmented by obesity in OSA may cause pharyngeal myopathy and influence central neuronal control of the upper airway muscles [24]. Thus, upper airway inflammation seems to be both a cause and consequence of OSA (Fig. 1).

Vibration trauma is less likely to contribute to lower airway inflammation. However, oxidative stress caused by CIH may affect $25-70 \mathrm{~m}^{2}$ [29] of the intrathoracic airway tract. In vitro studies have shown that intermittent hypoxia enhances neutrophil chemotaxis and leads to the production of matrix metalloproteinase (MMP)-2, MMP-9, interleukin (IL)8, platelet derived growth factor-AA, and vascular endothelial growth factor (VEGF) by airway epithelial cells and VEGF by bronchial smooth muscle cells [30]. Chronic intermittent hypoxia activates nuclear factor-kappaB in mice lungs in vivo and in monocytes of patients with OSA in vitro and theoretically induces the production of tumor necrosis factor (TNF)- $\alpha$, IL-6, IL-8, IL-18, and intercellular adhesion molecule (ICAM)-1 [31]. In ovalbumin-sensitized rats, CIH induced Th1type airway inflammation and airway narrowing [32]. A disturbed sleep profile is another characteristic of OSA. In mice, sleep deprivation exacerbated endotoxin-induced lung inflammation [33,34], which suggests that sleep fragmentation may correspond to augmented airway inflammation.

Studies that used induced sputum for sampling showed neutrophilia in the airways of adult [26,35-41] and pediatric [42] patients with OSA, without any change in the eosinophil or lymphocyte counts. In addition, in the evaluation for soluble mediators in sputum and exhaled breath condensate (EBC) samples, elevated levels of IL-6 [43-47], IL-8 [36,40], TNF$\alpha$ [44-46,48], ICAM [40], 8-isoprostane [43-47,49-51], $\mathrm{H}_{2} \mathrm{O}_{2}$ [51,52], uric acid [53], nitrate [51], leptin [41], leukotriene B4 [51,54], and cysteinyl leukotrienes [54] and decreased concentrations of IL-10 [44,46] and sirtuin 1 [48] were reported; airway acidosis $[38,45,51]$ was also reported. However, other studies reported no differences in airway $\mathrm{pH}$ [55] and cysteinyl leukotriene [54], prostaglandin E2 [54], and erythropoietin [56] levels.

Increased expression of inducible nitric oxide synthase (iNOS) by airway neutrophil cells and macrophages was

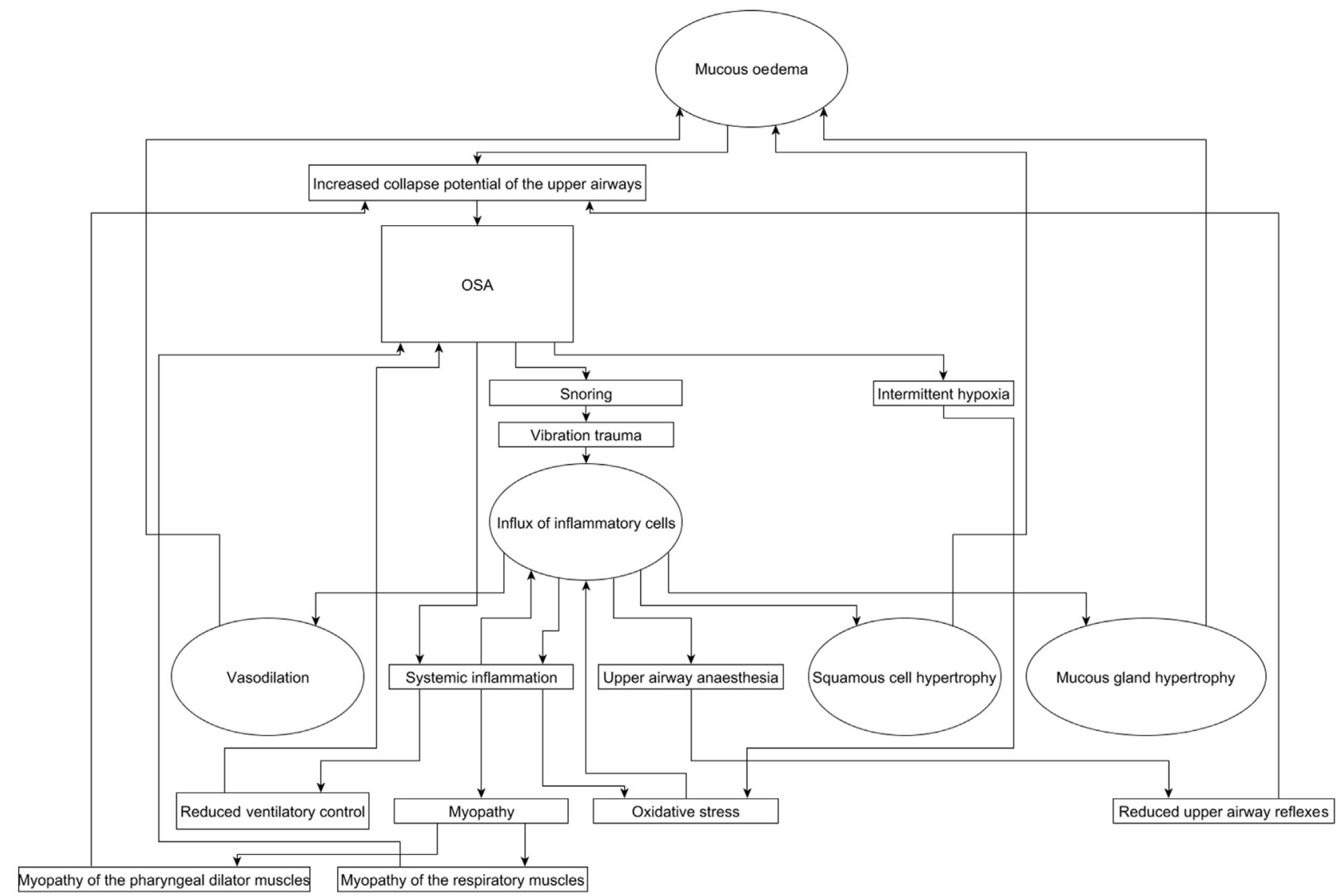

Fig. 1 - Upper airway inflammation in obstructive sleep apnea. Snoring and intermittent hypoxia lead to inflammatory and structural changes in the upper airways (highlighted in ellipses). Mucosal edema reduces the pharyngeal diameter. In addition, upper airway inflammation corresponds to decreased activity of the upper airway dilator muscles via reduced reflexes and myopathy and enhances systemic inflammatory processes. 
reported in OSA [39]. Upon stimulation by IL-1, interferon- $\gamma$, or TNF- $\alpha$, neutrophils may produce nitric oxide via iNOS [57]. Nitric oxide excess in the airways can be detected from exhaled breath (fractional exhaled nitric oxide, FENO). FENO was shown to be elevated in OSA in some [36,38,39,51,58-61] but not all studies [62-66]. Because of methodological discrepancies, these studies cannot be easily compared. However, taken together, a mild increase in FENO can be concluded [67]. The levels of exhaled carbon monoxide, a marker of oxidative stress, were also found to be elevated in OSA [51].

Exhaled breath contains thousands of volatile molecules and their concentration is related to airway and systemic inflammation as well as metabolism [68]. The pattern of exhaled volatile metabolites has been extensively investigated in OSA using so called electronic noses [67]. Various studies have reported altered exhaled volatile organic compound patterns in adult $[55,69,70]$ and pediatric $[71]$ patients with OSA. In addition, a recent study observed differences in the exhaled volatile compound concentrations of patients with OSA and those with COPD and the COPD-OSA overlap syndrome [72]. The breath pattern was correlated with the disease severity in the adults [55] and children [71]. The exhaled volatile molecular pattern was significantly altered by sleep [69] and CPAP [55,73]. However, CPAP-induced changes were significantly dependent on comorbidities [73]. Because of the nonspecific nature of electronic nose measurements, the individual molecules responsible for the differences in OSA are not known. Elevated levels of exhaled butanol [74], toluene, ethylbenzene, p-xylene, phenylacetic acid, hexane, heptane, octane, nonane, decane, acetone, and isoprene [75] as well as an overnight increase in exhaled pentane [64] were reported in OSA. In addition, CPAP withdrawal resulted in alterations in the concentrations of several volatile organic compounds [76].

Some studies investigated airway inflammation in patients who suffered from concomitant OSA and COPD. Upon analyzing bronchoalveolar lavage fluid (BALF) samples, Wang et al. reported a higher elevation in airway neutrophilia in the overlap syndrome than in COPD alone [77]. In contrast, Lacedonia et al. reported similar neutrophil counts in induced sputum samples [35]. The discrepancies may be because of the low sample size in the latter study, as neutrophil counts tended to be higher in the overlap group $(74.33 \% \pm 14.8)$ than in the COPD group $(63.33 \% \pm 13.22)$ [35]. In the analysis of BALF cytokines, the COPD-OSA overlap syndrome was characterized by elevated levels of TNF- $\alpha$ and IL-8 compared with COPD alone [77]. In patients with severe asthma, OSA resulted in higher levels of sputum IL-8 and subsequent sputum neutrophilia [78].

Similar to that in the upper airways, inflammation in the lungs may not only be a consequence of chronic intermittent hypoxia and vibration trauma but may also contribute to the pathophysiology of OSA. Local inflammatory cytokines may overspill into circulation, contributing to lowgrade systemic inflammation, which is present in OSA [79]. It was shown that the vascular permeability index is increased in OSA and is significantly related to disease severity [80]. In line with this, exhaled and circulating levels of 8-isoprostane were significantly correlated with each other [50]. However, another study found no correlation between the circulating and sputum levels of the investigated inflammatory mediators [80]. In conclusion, more studies are warranted to confirm or reject the overspill hypothesis. On the other hand, airway inflammation may induce airway narrowing, which has been recently confirmed in OSA [80]. Nevertheless, significant associations were reported between the magnitude of airway inflammation and OSA severity [38-40,43,46,48-52,60].

Obesity may aggravate airway inflammation. However, studies examining airway inflammation in obese individuals usually did not take into consideration the possible effect of OSA. Lacedonia et al. investigated the cellular pattern of the induced sputum of non-OSA obese patients and found no difference compared to that of non-OSA nonobese controls [35]. Of note, neutrophil cell counts tended to be higher in obese patients $(43.5 \% \pm 17.49)$ than in nonobese controls $(32.04 \% \pm 12.26)$ [35]. In OSA, a significant association was found between BMI and the sputum levels of IL-6 [80]. In line with this, two studies reported airway neutrophilia and elevated FENO levels in obese non-OSA subjects compared with controls [38,39]. However, both studies concluded that OSA had an additional effect on airway inflammation when the obese subjects were divided into OSA and non-OSA groups [38,39]. In contrast, although obesity was associated with higher EBC IL-8 and ICAM-1 levels in non-OSA subjects, OSA did not induce further elevation of EBC IL-8 and ICAM-1 levels in obese volunteers [40]. Finally, the levels of EBC leptin were higher in obese than in non-obese non-OSA subjects [41].

It is not clear how treating OSA affects airway inflammation. On analyses of BALF samples, CPAP was found to significantly reduce the neutrophil count as well as TNF- $\alpha$ and IL-8 levels in patients with the COPD-OSA overlap syndrome. However, the subjects used inhaled corticosteroids as well, which might have influenced the results [77]. In contrast, CPAP had no effect on sputum neutrophilia in OSA $[26,36]$. In the investigation of soluble mediators, CPAP was found to significantly decrease the levels of IL-6 [44,81], 8 -isoprostane $[44,49,50,81]$, TNF- $\alpha[44,48,81]$, and nitrotyrosine [81] and increase the IL-10 [44] and sirtuin 1 concentrations [48] as well as $\mathrm{pH}$ [51] in the airways. However, other studies have reported that CPAP treatment did not significantly change the exhaled carbon monoxide [51], EBC IL-6 [82], $\mathrm{H}_{2} \mathrm{O}_{2}$ [51], 8-isoprostane [51], nitrate [51,82], LTB4 [51], or pH $[55,82]$ values. Similarly, CPAP was found to decrease FENO in some $[51,58,60]$ but not all $[36,63]$ studies. A possible reason for the inconsistent results is that CPAP therapy may itself exacerbate airway inflammation due to mechanical trauma. This is in line with its effect on airway hyperresponsiveness $[36,83,84]$. Using heated humidification with CPAP could be a possible solution, as this is more effective in reducing airway [36] and nasal [85] inflammation. Upper airway surgery did not change the EBC IL-6 levels or EBC pH significantly [82]. 


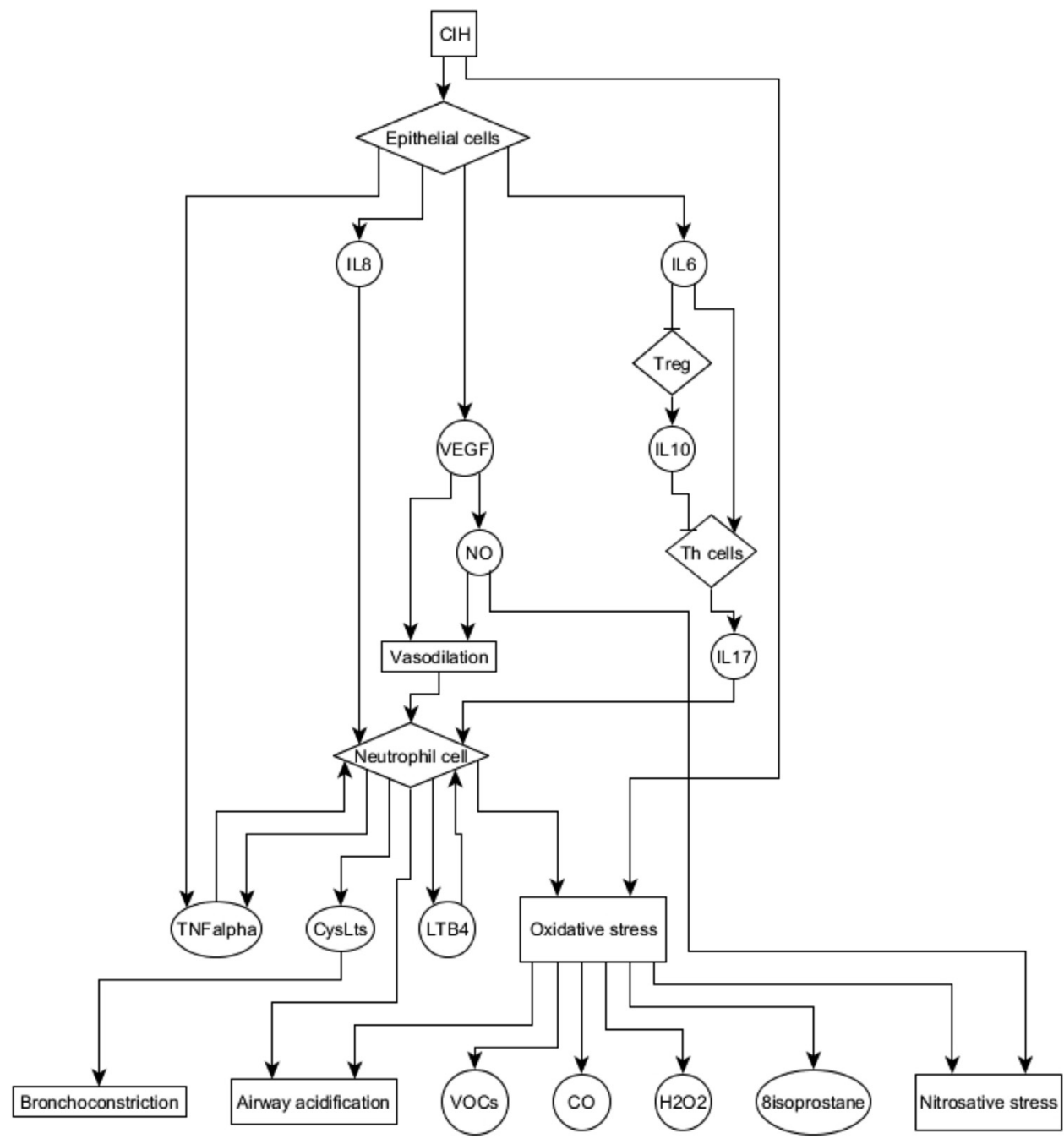

Fig. 2 - Elements of airway inflammation in obstructive sleep apnea. Chronic intermittent hypoxia (CIH) induces production of pro-inflammatory cytokines, including interleukin (IL)-6, IL-8, and tumor necrosis factor (TNF)-alpha as well as VEGF. These induce neutrophil cell and lymphocyte influx, which potentiate oxidative and nitrosative stress, bronchoconstriction, and airway acidification and accelerate airway inflammation through positive feedback mechanisms. In addition, increased production of VEGF and nitric oxide leads to bronchial vasodilation. This not only facilitates the influx of circulating inflammatory cells toward airway mucous but also allows overspill of airway inflammatory cytokines and markers of oxidative and nitrosative stress into circulation.

\section{Summary}

Obstructive sleep apnea may trigger lower airway inflammation primarily through intermittent hypoxia and oxidative stress and secondarily through vibration trauma and sleep fragmentation. This inflammation is characterized by type 1 cytokines and airway neutrophilia (Fig. 2). Obesity, a major co-factor in OSA pathophysiology, may directly affect airway inflammation and may also worsen overnight hypoxia [18], accelerating OSA-induced changes in the airways. The reduction in lung volumes, either induced by parenchymal lung disease or obesity, would worsen OSA due to anatomical, chemical, and neuronal factors.

Currently, information on whether treating OSA with CPAP improves airway function and inflammation is limited.
This highlights the need for the development of pharmacological anti-inflammatory treatments for OSA. However, to date, data on the effects of these drugs are very limited.

\section{Funding}

Hungarian Academy of Sciences provided fellowship during preparation the manuscript. The sponsor was not involved in writing the report.

\section{Conflict of interest}

The authors have no conflicts of interest. 


\section{Acknowledgements}

This publication was supported by the Janos Bolyai Research Scholarship of the Hungarian Academy of Sciences granted to Andras Bikov.

\section{R E F E R E N C E S}

[1] American Academy of Sleep Medicine. The international classification of sleep disorders, 3rd edition. Darien, IL, USA: AASM Resource Library; 2014.

[2] Gislason T, Sunnergren O. Obstructive sleep apnoea in adults. In: Annesi-Maesano I, Viegi G, Lundback B, European respiratory monograph. Respiratory epidemiology. Norwich, UK: European Respiratory Society; 2014. p. 88-105. http://dx. doi.org/10.1183/2312508X.erm6514.

[3] Aihara K, Oga T, Harada Y, Chihara Y, Handa T, Tanizawa K, et al. Analysis of anatomical and functional determinants of obstructive sleep apnea. Sleep Breath 2012;16:473-81.

[4] Abdeyrim A, Li N, Shao L, Heizhati M, Wang Y, Yao X, et al. What can impulse oscillometry and pulmonary function testing tell us about obstructive sleep apnea: a case-control observational study? Sleep Breath 2016;20:61-8.

[5] Abdeyrim A, Tang L, Muhamat A, Abudeyrim K, Zhang Y, Li $\mathrm{N}$, et al. Receiver operating characteristics of impulse oscillometry parameters for predicting obstructive sleep apnea in preobese and obese snorers. BMC Pulm Med 2016;16:125.

[6] Ozturk L, Metin G, Cuhadaroglu C, Utkusavas A, Tutluoglu B. FEF(25-75)/FVC measurements and extrathoracic airway obstruction in obstructive sleep apnea patients. Sleep Breath 2005;9:33-8.

[7] Kunos L, Lazar Z, Martinovszky F, Tarnoki AD, Tarnoki DL, Kovacs D, et al. Overnight changes in lung function of obese patients with obstructive sleep apnoea. Lung 2017;195:127-33.

[8] Zerah-Lancner F, Lofaso F, Coste A, Ricolfi F, Goldenberg F, Harf A. Pulmonary function in obese snorers with or without sleep apnea syndrome. Am J Respir Crit Care Med 1997;156:522-7.

[9] Veale D, Chailleux E, Hoorelbeke-Ramon A, Reybet-Degas O, Humeau-Chapuis MP, Alluin-Aigouy F, et al. Mortality of sleep apnoea patients treated by nasal continuous positive airway pressure registered in the ANTADIR observatory. Association Nationale pour le Traitement A Domicile de l'Insuffisance Respiratoire chronique. Eur Respir J 2000;15:326-31.

[10] Putcha N, Crainiceanu C, Norato G, Samet J, Quan SF, Gottlieb DJ, et al. Influence of lung function and sleep-disordered breathing on all-cause mortality. A community-based study. Am J Respir Crit Care Med 2016;194:1007-14.

[11] Malhotra A, Hillman D. Obesity and the lung: 3. Obesity, respiration and intensive care. Thorax 2008;63:925-31.

[12] Pihtili A, Bingol Z, Kiyan E, Cuhadaroglu C, Issever H Gulbaran Z. Obstructive sleep apnea is common in patients with interstitial lung disease. Sleep Breath 2013;17:1281-8.

[13] Biselli P, Grossman PR, Kirkness JP, Patil SP, Smith PL, Schwartz AR, et al. The effect of increased lung volume in chronic obstructive pulmonary disease on upper airway obstruction during sleep. J Appl Physiol 1985;2015 (119):266-71.

[14] Heinzer RC, Stanchina ML, Malhotra A, Fogel RB, Patel SR, Jordan AS, et al. Lung volume and continuous positive airway pressure requirements in obstructive sleep apnea. Am J Respir Crit Care Med 2005;172:114-7.
[15] Owens RL, Malhotra A, Eckert DJ, White DP, Jordan AS. The influence of end-expiratory lung volume on measurements of pharyngeal collapsibility. J Appl Physiol 1985;2010 (108):445-51.

[16] Van de Graaff WB. Thoracic influence on upper airway patency. J Appl Physiol 1985;1988(65):2124-31.

[17] Younes M, Ostrowski M, Thompson W, Leslie C, Shewchuk W. Chemical control stability in patients with obstructive sleep apnea. Am J Respir Crit Care Med 2001;163:1181-90.

[18] Jordan AS, McSharry DG, Malhotra A. Adult obstructive sleep apnoea. Lancet 2014;383:736-47.

[19] Ballard RD, Irvin CG, Martin RJ, Pak J, Pandey R, White DP. Influence of sleep on lung volume in asthmatic patients and normal subjects. J Appl Physiol 1985;1990(68):2034-41.

[20] Stadler DL, McEvoy RD, Bradley J, Paul D, Catcheside PG. Changes in lung volume and diaphragm muscle activity at sleep onset in obese obstructive sleep apnea patients vs. healthy-weight controls. J Appl Physiol 1985;2010 (109):1027-36.

[21] Lindner KH, Lotz P, Ahnefeld FW. Continuous positive airway pressure effect on functional residual capacity, vital capacity and its subdivisions. Chest 1987;92:66-70.

[22] Bonay M, Nitenberg A, Maillard D. Should flow-volume loop be monitored in sleep apnea patients treated with continuous positive airway pressure? Respir Med 2003;97:830-4.

[23] Rasche K, Duchna HW, Lauer J, Orth M, Kotterba S, Bauer TT, et al. Obstructive sleep apnea and hypopnea efficacy and safety of a long-acting beta2-agonist. Sleep Breath 1999;3:125-30.

[24] Hatipoglu U, Rubinstein I. Inflammation and obstructive sleep apnea syndrome pathogenesis: a working hypothesis. Respiration 2003;70:665-71.

[25] Rubinstein I. Nasal inflammation in patients with obstructive sleep apnea. Laryngoscope 1995;105:175-7.

[26] Lacedonia D, Salerno FG, Carpagnano GE, Sabato R, Depalo A, Foschino-Barbaro MP. Effect of CPAP-therapy on bronchial and nasal inflammation in patients affected by obstructive sleep apnea syndrome. Rhinology 2011;49:232-7.

[27] Vicente E, Marin JM, Carrizo SJ, Osuna CS, Gonzalez R, MarinOto $\mathrm{M}$, et al. Upper airway and systemic inflammation in obstructive sleep apnoea. Eur Respir J 2016;48:1108-17.

[28] Hauber HP, Ruller S, Muller E, Hansen E, Zabel P. Pharyngeal lavage lymphocytosis in patients with obstructive sleep apnea: a preliminary observation. PLoS One 2011;6:e16277.

[29] Hasleton PS. The internal surface area of the adult human lung. J Anat 1972;112:391-400.

[30] Philippe C, Boussadia Y, Pruliere-Escabasse V, Papon JF, Clerici C, Isabey D, et al. Airway cell involvement in intermittent hypoxia-induced airway inflammation. Sleep Breath 2015;19:297-306.

[31] Greenberg H, Ye X, Wilson D, Htoo AK, Hendersen T, Liu SF Chronic intermittent hypoxia activates nuclear factor-kap$\mathrm{paB}$ in cardiovascular tissues in vivo. Biochem Biophys Res Commun 2006;343:591-6.

[32] Broytman O, Braun RK, Morgan BJ, Pegelow DF, Hsu PN, Mei LS, et al. Effects of chronic intermittent hypoxia on allergeninduced airway inflammation in rats. Am J Respir Cell Mol Biol 2015;52:162-70.

[33] Kim JY, Lee YD, Kim BJ, Kim SP, Kim DH, Jo KJ, et al. Melatonin improves inflammatory cytokine profiles in lung inflammation associated with sleep deprivation. Mol Med Rep 2012;5:1281-4

[34] Lee YD, Kim JY, Lee KH, Kwak YJ, Lee SK, Kim OS, et al. Melatonin attenuates lipopolysaccharide-induced acute lung inflammation in sleep-deprived mice. J Pineal Res 2009;46:53-7.

[35] Lacedonia D, Salerno FG, Sabato R, Carpagnano GE, Aliani M, Palladino GP, et al. Airway cell patterns in patients suffering 
from COPD and OSAS (Overlap Syndrome). Respir Med 2011;105:303-9.

[36] Devouassoux G, Levy P, Rossini E, Pin I, Fior-Gozlan M, Henry $\mathrm{M}$, et al. Sleep apnea is associated with bronchial inflammation and continuous positive airway pressure-induced airway hyperresponsiveness. J Allergy Clin Immunol 2007;119:597-603.

[37] Salerno FG, Carpagnano E, Guido P, Bonsignore MR, Roberti A, Aliani M, et al. Airway inflammation in patients affected by obstructive sleep apnea syndrome. Respir Med 2004;98:25-8.

[38] Carpagnano GE, Spanevello A, Sabato R, Depalo A, Turchiarelli V, Foschino Barbaro MP. Exhaled pH, exhaled nitric oxide, and induced sputum cellularity in obese patients with obstructive sleep apnea syndrome. Transl Res 2008;151:45-50.

[39] Depalo A, Carpagnano GE, Spanevello A, Sabato R, Cagnazzo MG, Gramiccioni C, et al. Exhaled NO and iNOS expression in sputum cells of healthy, obese and OSA subjects. J Intern Med 2008;263:70-8.

[40] Carpagnano GE, Spanevello A, Sabato R, Depalo A, Palladino GP, Bergantino L, et al. Systemic and airway inflammation in sleep apnea and obesity: the role of ICAM-1 and IL-8. Transl Res 2010;155:35-43.

[41] Carpagnano GE, Resta O, Pergola GD, Sabato R, Foschino Barbaro MP. The role of obstructive sleep apnea syndrome and obesity in determining leptin in the exhaled breath condensate. J Breath Res 2010;4:036003.

[42] Li AM, Hung E, Tsang T, Yin J, So HK, Wong E, et al. Induced sputum inflammatory measures correlate with disease severity in children with obstructive sleep apnoea. Thorax 2007;62:75-9.

[43] Carpagnano GE, Kharitonov SA, Resta O, Foschino-Barbaro MP, Gramiccioni E, Barnes PJ. Increased 8-isoprostane and interleukin- 6 in breath condensate of obstructive sleep apnea patients. Chest 2002;122:1162-7.

[44] Li Y, Chongsuvivatwong V, Geater A, Liu A. Are biomarker levels a good follow-up tool for evaluating obstructive sleep apnea syndrome treatments? Respiration 2008;76:317-23.

[45] Antonopoulou S, Loukides S, Papatheodorou G, Roussos C, Alchanatis M. Airway inflammation in obstructive sleep apnea: is leptin the missing link? Respir Med 2008;102:1399-405.

[46] Li Y, Chongsuvivatwong V, Geater A, Liu A. Exhaled breath condensate cytokine level as a diagnostic tool for obstructive sleep apnea syndrome. Sleep Med 2009;10:95-103.

[47] Biltagi MA, Maguid MA, Ghafar MA, Farid E. Correlation of 8-isoprostane, interleukin- 6 and cardiac functions with clinical score in childhood obstructive sleep apnoea. Acta Paediatr 2008;97:1397-405.

[48] Lin CC, Liaw SF, Chiu CH, Chen WJ, Lin MW, Chang FT. Effects of nasal CPAP on exhaled SIRT1 and tumor necrosis factoralpha in patients with obstructive sleep apnea. Respir Physiol Neurobiol 2016;228:39-46.

[49] Fernandez Alvarez R, Rubinos Cuadrado G, Alonso Arias R, Cascon Hernandez JA, Palomo Antequera B, Iscar Urrutia M, et al. Snoring as a determinant factor of oxidative stress in the airway of patients with obstructive sleep apnea. Lung 2016;194:469-73.

[50] Carpagnano GE, Kharitonov SA, Resta O, Foschino-Barbaro MP, Gramiccioni E, Barnes PJ. 8-Isoprostane, a marker of oxidative stress, is increased in exhaled breath condensate of patients with obstructive sleep apnea after night and is reduced by continuous positive airway pressure therapy. Chest 2003;124:1386-92.

[51] Petrosyan M, Perraki E, Simoes D, Koutsourelakis I, Vagiakis E, Roussos C, et al. Exhaled breath markers in patients with obstructive sleep apnoea. Sleep Breath 2008;12:207-15.
[52] Malakasioti G, Alexopoulos E, Befani C, Tanou K, Varlami V, Ziogas D, et al. Oxidative stress and inflammatory markers in the exhaled breath condensate of children with OSA. Sleep Breath 2012;16:703-8.

[53] Vlasic V, Trifunovic J, Cepelak I, Nimac P, Topic RZ, Dodig S. Urates in exhaled breath condensate of children with obstructive sleep apnea. Biochem Med 2011;21:139-44.

[54] Goldbart AD, Krishna J, Li RC, Serpero LD, Gozal D. Inflammatory mediators in exhaled breath condensate of children with obstructive sleep apnea syndrome. Chest 2006;130:143-8.

[55] Greulich T, Hattesohl A, Grabisch A, Koepke J, Schmid S, Noeske S, et al. Detection of obstructive sleep apnoea by an electronic nose. Eur Respir J 2013;42:145-55.

[56] Schumann C, Triantafilou K, Krueger S, Hombach V, Triantafilou M, Becher G, et al. Detection of erythropoietin in exhaled breath condensate of nonhypoxic subjects using a multiplex bead array. Mediat Inflamm 2006;2006:18061.

[57] Evans TJ, Buttery LD, Carpenter A, Springall DR, Polak JM, Cohen J. Cytokine-treated human neutrophils contain inducible nitric oxide synthase that produces nitration of ingested bacteria. Proc Natl Acad Sci USA 1996;93:9553-8.

[58] Chua AP, Aboussouan LS, Minai OA, Paschke K, Laskowski D, Dweik RA. Long-term continuous positive airway pressure therapy normalizes high exhaled nitric oxide levels in obstructive sleep apnea. J Clin Sleep Med 2013;9:529-35.

[59] Przybylowski T, Bielicki P, Kumor M, Hildebrand K, MaskeyWarzechowska M, Fangrat A, et al. [Exhaled nitric oxide in patients with obstructive sleep apnea syndrome]. Pneumonol Alergol Pol 2006;74:21-5.

[60] Fortuna AM, Miralda R, Calaf N, Gonzalez M, Casan P, Mayos M. Airway and alveolar nitric oxide measurements in obstructive sleep apnea syndrome. Respir Med 2011;105:630-6.

[61] Culla B, Guida G, Brussino L, Tribolo A, Cicolin A, Sciascia S, et al. Increased oral nitric oxide in obstructive sleep apnoea. Respir Med 2010;104:316-20.

[62] Agusti AG, Barbe F, Togores B. Exhaled nitric oxide in patients with sleep apnea. Sleep 1999;22:231-5.

[63] Foresi A, Leone C, Olivieri D, Cremona G. Alveolar-derived exhaled nitric oxide is reduced in obstructive sleep apnea syndrome. Chest 2007;132:860-7.

[64] Olopade CO, Christon JA, Zakkar M, Hua C, Swedler WI, Scheff PA, et al. Exhaled pentane and nitric oxide levels in patients with obstructive sleep apnea. Chest 1997;111:1500-4.

[65] JalilMirmohammadi S, Mehrparvar AH, Safaei S, Samimi E, Torab Jahromi M. The association between exhaled nitric oxide and sleep apnea: the role of BMI. Respir Med 2014;108:1229-33.

[66] Hua-Huy T, Le-Dong NN, Duong-Quy S, Luchon L, Rouhani S, Dinh-Xuan AT. Increased alveolar nitric oxide concentration is related to nocturnal oxygen desaturation in obstructive sleep apnoea. Nitric Oxide 2015;45c:27-34.

[67] Bikov A, Hull JH, Kunos L. Exhaled breath analysis, a simple tool to study the pathophysiology of obstructive sleep apnoea. Sleep Med Rev 2016;27:1-8.

[68] Bikov A, Lazar Z, Horvath I. Established methodological issues in electronic nose research: how far are we from using these instruments in clinical settings of breath analysis? J Breath Res 2015;9:034001.

[69] Kunos L, Bikov A, Lazar Z, Korosi BZ, Benedek P, Losonczy G, et al. Evening and morning exhaled volatile compound patterns are different in obstructive sleep apnoea assessed with electronic nose. Sleep Breath 2015;19:247-53.

[70] Dragonieri S, Porcelli F, Longobardi F, Carratu P, Aliani M, Ventura VA, et al. An electronic nose in the discrimination of 
obese patients with and without obstructive sleep apnoea. J Breath Res 2015;9:026005.

[71] Benedek P, Lazar Z, Bikov A, Kunos L, Katona G, Horvath I. Exhaled biomarker pattern is altered in children with obstructive sleep apnoea syndrome. Int J Pediatr Otorhinolaryngol 2013;77:1244-7.

[72] Dragonieri S, Quaranta VN, Carratu P, Ranieri T, Resta O. Exhaled breath profiling in patients with COPD and OSA overlap syndrome: a pilot study. J Breath Res 2016;10:041001.

[73] Antonelli Incalzi R, Pennazza G, Scarlata S, Santonico M, Vernile C, Cortese L, et al. Comorbidity modulates non invasive ventilation-induced changes in breath print of obstructive sleep apnea syndrome patients. Sleep Breath 2015;19:623-30.

[74] Bayrakli I, Ozturk O, Akman H. Investigation of acetone, butanol and carbon dioxide as new breath biomarkers for convenient and noninvasive diagnosis of obstructive sleep apnea syndrome. Biomed Chromatogr 2016.

[75] Aoki T, Nagaoka T, Kobayashi N, Kurahashi M, Tsuji C, Takiguchi H, et al. Editor's highlight: prospective analyses of volatile organic compounds in obstructive sleep apnea patients. Toxicol Sci 2017;156:362-74.

[76] Schwarz EI, Martinez-Lozano Sinues P, Bregy L, Gaisl T, Garcia Gomez D, Gaugg MT, et al. Effects of CPAP therapy withdrawal on exhaled breath pattern in obstructive sleep apnoea. Thorax 2016;71:110-7.

[77] Wang Y, Hu K, Liu K, Li Z, Yang J, Dong Y, et al. Obstructive sleep apnea exacerbates airway inflammation in patients with chronic obstructive pulmonary disease. Sleep Med 2015;16:1123-30.
[78] Taille C, Rouvel-Tallec A, Stoica M, Danel C, Dehoux M, Marin-Esteban V, et al. Obstructive sleep apnoea modulates airway inflammation and remodelling in severe asthma. PLoS One 2016;11:e0150042.

[79] Kohler M. Why should we care about upper airway inflammation in obstructive sleep apnoea? Eur Respir J 2016;48:982-3.

[80] Aihara K, Oga T, Chihara Y, Harada Y, Tanizawa K, Handa T, et al. Analysis of systemic and airway inflammation in obstructive sleep apnea. Sleep Breath 2013;17:597-604.

[81] Karamanli H, Ozol D, Ugur KS, Yildirim Z, Armutcu F, Bozkurt $B$, et al. Influence of CPAP treatment on airway and systemic inflammation in OSAS patients. Sleep Breath 2014;18:251-6.

[82] Lloberes P, Sanchez-Vidaurre S, Ferre A, Cruz MJ, Lorente J, Sampol G, et al. Effect of continuous positive airway pressure and upper airway surgery on exhaled breath condensate and serum biomarkers in patients with sleep apnea. Arch Bronconeumol 2014;50:422-8.

[83] Wenzel G, Schonhofer B, Wenzel M, Kohler D. [Bronchial hyperreactivity and nCPAP therapy]. Pneumologie 1997;51 (Suppl. 3):S770-2.

[84] Korczynski P, Gorska K, Przybylowski T, Bielicki P, Zielinski J, Chazan R. Continuous positive airway pressure treatment increases bronchial reactivity in obstructive sleep apnea patients. Respiration 2009;78:404-10.

[85] Koutsourelakis I, Vagiakis E, Perraki E, Karatza M, Magkou C, Kopaka M, et al. Nasal inflammation in sleep apnoea patients using CPAP and effect of heated humidification. Eur Respir J 2011;37:587-94. 